\title{
Reasons for low adherence to diet-diaries issued to pediatric dental patients: a collective case study
}

This article was published in the following Dove Press journal:

Patient Preference and Adherence

\author{
Arheiam Arheiam ${ }^{1,2}$ \\ Sondos Albadri ${ }^{3}$ \\ Louise Laverty ${ }^{2}$ \\ Rebecca Harris ${ }^{2}$ \\ 'Department of Community and \\ Preventive Dentistry, Faculty of \\ Dentistry, University of Benghazi, \\ Libya; ${ }^{2}$ Department of Health Services \\ Research, University of Liverpool, \\ Liverpool, UK; ${ }^{3}$ Department of \\ Paediatric Dentistry, School of \\ Dentistry, University of Liverpool, \\ Liverpool, UK
}

Objective: Dietary habits are an important etiological factor in the development of dental caries. Several tools, such as 24-h dietary recall (retrospective) and diet-diaries (prospective), have been recommended for dietary assessment in dental practice. Diet-diaries are commonly advocated as a tool for oral health education; however, low adherence is found to be a recognized downside of their use in dental settings, as well as nutritional research more widely. However, the reasons for poor adherence to diet-diaries remain unclear. This study aimed to explore the reasons for poor adherence to diet-diaries issued to children in a dental hospital setting.

Methods: A qualitative collective case study design was employed to explore the use of dietdiaries as a health education tool. Twenty-eight data sources across 11 appointments included: observation of dentist-patient interactions, semi-structured interviews with child-parent dyads and dentists, in addition to documentary analysis of returned diet-diaries (this included 11 observations of dentist-patient interactions, 14 interviews with the child/parent dyads and dentists, and documentary analysis of three completed diet-diaries). Data from these multiple sources were integrated in a thematic analysis to identify themes and sub-themes.

Results: Two overarching themes were identified: 1) the diet-diary is perceived as a test which carries a potential for embarrassment and blame, which in turn generates defensive behavior from parents; and 2) parents' values, priorities, and circumstances affect the level of commitment to completing a diet-diary.

Conclusion: Low adherence to diet-diary completion in clinical dentistry results from interacting factors related to the diet-diary itself, the patient, and the clinician. This study identifies a need for a more appropriate tool for dietary assessment that is patient-centered and compatible with modern lifestyles.

Keywords: adherence, diet, health education, children, dental, dietary advice

\section{Introduction}

Discussing sugar consumption with patients in dental care settings has the potential to benefit both oral and general health, since sugar behavior impacts not only the likelihood of developing dental caries, but a range of other chronic health problems too. ${ }^{1,2}$ While the giving of generic dietary advice to reduce sugar consumption and promote healthy eating is recommended for all dental patients, ${ }^{2}$ there is a general consensus that dietary advice tailored to patients' needs and circumstances is best. ${ }^{3}$ Thus, a detailed dietary assessment is seen as an appropriate intervention for dental teams, for patients identified to be at high risk of dental caries and tooth erosion., ${ }^{4,5}$ There are main methods of dietary assessment which can be generally classified as retrospective and prospective methods. The most popular retrospective method is 24-h dietary recall - although this method has been found to be time consuming, liable to memory distortion, and may not be representative of the habitual intake, since it covers only
Correspondence: Arheiam Arheiam Department of Community and Preventive Dentistry, Faculty of Dentistry, University of Benghazi, Jamal Abdelnaser Street, 7th floor, Room 703, Benghazi, Libya

Tel +2I 89I02984I4

Email arheiam@gmail.com 
1 day. ${ }^{4}$ An alternative approach is to generate a prospective diet history by keeping a diet-diary. Guidelines recommend that these patients are asked to provide a detailed account of timing, type, and structure of everything eaten or drunk for at least three consecutive days, one of which should be a weekend day. ${ }^{4,6,7}$

A recent study has found that, while diet-diaries are advocated as an appropriate way to collect this information, they are relatively infrequently used in NHS dental practice. ${ }^{8}$ A questionnaire study identified that dentists perceived, first, that there was insufficient remuneration for clinical time spent on administration and interpretation of diet-diaries to merit the activity; second, that they had insufficient knowledge/ skills in this area to analyze the information generated properly; and, third, that patients' only poorly adhered to requests to complete and return the diet record. ${ }^{8,9}$ A further study undertaken in a hospital setting, which, therefore, removed the reimbursement issue, revealed that as many as $65 \%$ of pediatric dental patients failed to return a completed diet-diary once issued. Moreover, amongst the diaries that were returned, a range of important information was missing, so there was only partial adherence, at best. ${ }^{9}$

In nutritional and behavioral research, where dietdiaries are commonly used, adherence is recognized as a problem. ${ }^{10-13}$ However, there is a lack of empirical evidence with regards to the reasons for poor adherence to diet-diarykeeping in the dental setting. Moreover, since diet-diaries are still recommended as the dietary assessment method of choice in clinical dentistry, more insight into why patients often do not respond well to this approach is needed. Our study aim was to explore the reasons for poor adherence in the keeping of diet-diaries in the context of clinical dentistry, but may shed light on the problem with the use of diet-diaries in other settings too.

\section{Methods}

Ethics (reference 14/LO/1204) and NHS research governance approvals were obtained from the National Research Ethics Service (NRES) Committee London - Camberwell St Giles before commencing the study. Written informed consent was obtained from all parents or legal guardians/caregivers before taking part in the study. A qualitative approach was used to fit the exploratory nature of the study and to allow in-depth assessment of a phenomenon in its real life context. ${ }^{14,15} \mathrm{~A}$ collective case study design was adopted. ${ }^{14}$ This involves the exploration of the phenomenon across various cases, with data analysis taking a cross-case comparison approach. ${ }^{16}$
In this study, cases were defined as a single child patient and carer dyad. This methodology emphasizes depth of investigations and gathering data from multiple sources, rather than breadth (higher numbers of cases), and was adopted because the purpose of the study was to develop hypotheses.

\section{Sample}

The sample in qualitative studies is determined by the number of cases needed to arrive at a consistent interpretation of the phenomenon of interest, also known as data saturation. ${ }^{17}$

\section{Recruitment}

Cases were recruited between February and June 2016 from children/parents attending the Department of Paediatric Dentistry in a UK teaching hospital, which is a setting which provides secondary and tertiary dental care for children referred from dental practices and community dental services. Only those aged between 5 and 11 years of age, who had active dental caries, and had been given appointments with staff members to complete a course of treatment, were included in this study. Because of the exploratory nature of the study, no recruitment restrictions were applied based on the socioeconomic status of the parents. UK Dental Hospital staff are all salaried so there are no financial incentives which influence their clinical activity. There was a standard clinical protocol in place at this center involving diet-diaries being given to all children identified as high risk of developing dental caries. Diet-diaries were issued to children/parents at their first visit to the centre (visit 1, V1), with a request to complete it and bring it back with them to a subsequent appointment where preventive dental care, including dietary advice, is provided by dentists, dental care professionals, or undergraduate students supervised by clinical tutors (visit 2, V2).

\section{Data collection}

Multiple data sources for each case included the following: non-participant observations supported with field notes, semi-structured interviews of parents and clinicians involved in initial (V1) and follow-up visit (V2), and a documentary analysis of any returned diet-diaries.

Two sets of non-participant observations of dentistpatient encounters (V1 and V2) were undertaken for each case to capture dentist-patient interactions in relation to the use of diet-diaries. The observations were audiotaped and supported by field notes and memos written by the researcher who was physically present at the research site to systematically collect pertinent contextual data. This included noting 
non-verbal behaviors of all involved, such as the patient averting their eyes, etc. The focus of the observations was on the relevant study objectives. ${ }^{15}$

In-depth semi-structured, face-to-face interviews were carried out with the child/parent dyads and dentists. While the intention was to gather patient perspectives from both the child and parent, in practice it was difficult to interview the child. The patient's perspective was primarily obtained from the parent, and, therefore, the word "patient" in this paper refers to the parent. Two interviews were carried out with each child/parent dyad. The first interview took place immediately after the first observation when patients received the diet-diaries. This interview was designed to focus on the patient's thoughts and feelings towards diet-diaries. A follow-up interview was arranged with the patient for the subsequent appointment when they returned the diet-diaries to be discussed. The second interview aimed to explore child and parent's experiences of using diet-diaries. Another interview was arranged with the dentists who were involved in the study, after completing the preventive care visits, to reflect on their experiences of using diet-diaries. The interview also focused on issues that emerged from observations and interviews with child/parent dyads. Patients were informed that information disclosed during the interviews would be kept confidential and not disclosed to the clinicians involved in their care.

All the interviews were audio-recorded and undertaken in a quiet non-clinical setting. Each interview took between 30-45 min. Topic guides were used for each interview (see Supplementary materials), which were modified iteratively after each interview/observation and throughout the study to accommodate observations from the diaries or in the interviews. No set order of questions was followed, allowing the participants to freely connect different topic areas.

Returned diet-diaries were photocopied and transcribed verbatim to be analyzed for any issues relevant to the contextual data collected from interviews and observations of dentist-patient interactions.

\section{Data analysis}

In total, 28 data sources were collected pertinent to six cases (Table 1). This included 11 observations of dentist-patient interactions (six observations while diet-diaries were issued, and another five observations during the follow-up appointments - analysis of the diet-diary and the delivery of dietary advice), 14 interviews (five initial interviews, three follow-up interviews with the child/parent dyads, and six interviews with three dentists), and documentary analysis of three completed diet-diaries. Ages of child participants ranged from 9-11 years-old (Table 1). Three clinicians (two female, one male) were involved in the study.

All data sources were uploaded into NVIVIO 10 software and organized according to "case". This included all interviews, observations, field notes, and memos. Data analysis was conducted by thematic analysis (TA). ${ }^{18}$

The analysis was performed on a case-by-case basis in an iterative inductive-deductive process, using a cross-case comparison technique, to develop a preliminary coding framework. ${ }^{18}$ The preliminary framework was continually refined and adjusted according to the emerging themes and subsequent data collection. Thus, analysis was undertaken concurrently with data collection. During the analytic process, researcher's memos were written to increase the transparency of the analysis. Constant comparison across the cases and across different sources of data was applied so that emerging themes were based on converging the interpretation of all sets of data. ${ }^{19}$

Validity of analysis was assumed by involving a second researcher in the analysis who independently reviewed the data and contributed to the interpretation of the developing coding scheme (ie, as the analysis progressed, a discussion was held to remove unsupported themes, create new themes,

Table I Summary of available data sources

\begin{tabular}{lllllll}
\hline Case & $\begin{array}{l}\text { Age in } \\
\text { years }\end{array}$ & Data sources & & & \\
\cline { 3 - 6 } & & Interview I & Interview 2 & $\begin{array}{l}\text { Diet- } \\
\text { diary }\end{array}$ & $\begin{array}{l}\text { Dentist } \\
\text { interview }\end{array}$ & Observation I \\
\hline Case I & II & $\checkmark$ & $\times$ & $\checkmark$ & $\checkmark$ & $\checkmark$ \\
Case 2 & II & $\checkmark$ & $\checkmark$ & $\times$ & $\checkmark$ & $\checkmark$ \\
Case 3 & 9 & $\checkmark$ & $\checkmark$ & $\checkmark$ & $\checkmark$ \\
Case 4 & II & $\checkmark$ & $\times$ & $\times$ & $\checkmark$ \\
Case 5 & 9 & $\times$ & $\times$ & $\checkmark$ & $\checkmark$ \\
Case 6 & 9 & $\checkmark$ & $\checkmark$ & $\checkmark$ & $\checkmark$ & $\checkmark$ \\
\hline
\end{tabular}


collapse homogenous themes, and split heterogeneous ones). Analysis and data collection finished when new data did not alter the coding system substantially, but confirmed previous analysis. Finally, the themes were organized into fewer overarching themes.

The analysis was performed at an interpretive level rather than simply describing the surface meanings within the data. While the analysis can be classified as thematic analysis, it incorporated some elements of grounded theory approach, such as inductive approach, constant comparison, immediate analysis, memo writing, and theoretical saturation. ${ }^{20}$

\section{Results}

Two main themes and six sub-themes were identified. An overview of themes with conceptual definitions is given in Table 2. When providing supporting example quotes, pseudonyms are used to denote a participant dentist, whereas child/parent dyads are identified using case numbers.

\section{Theme I: a test perception and its outcomes}

In summary, we found that many parents were concerned that the diet-diary was something that their parenting style might be judged on. Parents expressed a perception that the dietdiary as a test that would be "marked" by a person in authority (the dentist) - with right and wrong answers, and that "failure" in the test could lead to a negative judgment of their

Table 2 Themes, sub-themes, and their conceptual definitions

\begin{tabular}{|c|c|c|}
\hline Main theme & Sub-theme & Conceptual definition \\
\hline \multirow[t]{3}{*}{$\begin{array}{l}\text { A test perception } \\
\text { and its outcomes }\end{array}$} & $\begin{array}{l}\text { Parents presenting } \\
\text { the best version of } \\
\text { themselves }\end{array}$ & $\begin{array}{l}\text { Parents try to present } \\
\text { the best versions of } \\
\text { themselves during dental } \\
\text { encounters }\end{array}$ \\
\hline & $\begin{array}{l}\text { Giving the "right" } \\
\text { answer }\end{array}$ & $\begin{array}{l}\text { Parents are generally } \\
\text { aware of what is the right } \\
\text { answer to "pass the test" }\end{array}$ \\
\hline & $\begin{array}{l}\text { Clinicians priming the } \\
\text { parents to think of the } \\
\text { diet-diary as a "test" }\end{array}$ & $\begin{array}{l}\text { Dentists behave in a way } \\
\text { that suggests to parents } \\
\text { the diet-diary is a test }\end{array}$ \\
\hline \multirow[t]{3}{*}{$\begin{array}{l}\text { User's values, } \\
\text { priorities, and } \\
\text { circumstances }\end{array}$} & $\begin{array}{l}\text { Relative position of } \\
\text { diet-diaries in the } \\
\text { hierarchy of priorities }\end{array}$ & $\begin{array}{l}\text { Parents' responsibilities } \\
\text { and how they rank the } \\
\text { importance of diet-diaries } \\
\text { activity relative to their } \\
\text { other everyday activities }\end{array}$ \\
\hline & $\begin{array}{l}\text { The parent-child } \\
\text { relationship }\end{array}$ & $\begin{array}{l}\text { Parents and children } \\
\text { have different interests } \\
\text { and views in relation to } \\
\text { diet-diaries }\end{array}$ \\
\hline & $\begin{array}{l}\text { A paper diet-diary } \\
\text { format is outmoded } \\
\text { and onerous }\end{array}$ & $\begin{array}{l}\text { A paper diet-diary does } \\
\text { not fit and is not valued } \\
\text { in a digital age }\end{array}$ \\
\hline
\end{tabular}

parenting style, with consequent shame and embarrassment. Data also showed that clinicians were in some part responsible for portraying the diet-diary activity as a test. This theme comprised the following three sub-themes:

\section{Parents presenting the best version of themselves}

People tend to behave in ways that present them as good and moral, and avoid behaviors that make them feel shamed and disgraced. ${ }^{21}$ Therefore, it is no surprise that parents were found to present the best versions of themselves during dental encounters when diet-diaries were issued, and in the interview which followed shortly afterwards. Parents' fear of shame was something explicitly expressed in interviews, and also observed during clinical interactions.

You want to look good in front of the dentist I think that's

very important for us, as human beings. [Case 2, parent,

follow-up interview]

Parents often portrayed themselves as considerate parents who cared about their child's oral health, valued health messages, and appreciated the value of diet-diaries. Some parents ostensibly expressed agreement with the dentist's advice, for example, by nodding their head, when the diet-diary was issued. Parents also expressed overt agreement with the importance of the diet-diaries task during a debrief interview with the researcher afterwards.

I think it will be good to know what is wrong with [child]'s diet. [Case 1, parent, debrief interview]

So, a diary will give us an idea as to where we are going

... where we are doing things in the wrong way and help

us correct it, so that's very useful that way. [Case 2, parent, debrief interview]

However, these outward expressions of support for the task were often not followed by compliance. While some of these parents who had articulated early support for the diet-diary, adhered to the task, others did not. On the second appointment, non-adherent parents gave different reasons for not doing the diet-diary task. The fear of creating a poor impression and risking judgment was clearly articulated by parents during the follow-up interviews.

When we faced the dental surgeon, we didn't want to look careless. [Case 2, parent, follow-up interview]

The situation of receiving advice about health behaviors for which an individual might be deemed responsible is particularly risky in relation to a possible loss of face. ${ }^{22}$ Avoiding or defensive behaviors (termed "hiding maneuvers") are a common reaction in such situations. ${ }^{21}$ Two 
kinds of hiding maneuvers were observed in the study. First, some parents completely avoided the diet-diary task, and offered a variety of excuses in order to "save face," although these were often viewed with scepticism by the dental team.

Normally it's "I've lost the diary, can I have another one?", "I've done it, but I've forgotten it." Some people are just generally honest and say "We didn't do it," as well. [Dentist interview, William]

Second, some parents temporarily modified diet behaviors or edited the dietary record to generate a version which would be more likely to be met with approval. One parent revealed that he avoided giving the child sweets while keeping the diary, and when asked why, said:

Because if you write sweets then you automatically think the dental surgeon will think "Oh he is eating sweets like this all the time," so that will give a bad impression. [Case 2, parent, follow-up interview]

This was despite the fact the dentist had been observed earlier emphasizing the importance of keeping an honest record of dietary intake:

We are not judging you. [Case 3, dentist, observation 1]

Don't change anything that you are already doing, just because you are filling this in, just be as sort of normal as you can really. [Case 2, dentist, observation 1]

\section{Giving the "right" answer}

Most parents appeared to be aware of what might be "correct" entries in a diet-diary. It was very uncommon for parents to attend an appointment without previous experience or knowledge of oral health, including dietary behaviors. Interviews revealed that some parents had already received dietary advice from previous encounters in dental practice (before referral to the hospital service).

I think two appointments ago Dr (NAME) he mentioned about dietary advice. We also get a lot of advice from our own general dentist. [Case 2, parent, follow-up interview]

Documentary analysis of returned diet-diaries provided further evidence that parents altered their responses in the diet history to generate accounts which would be more likely met with approval. For example, in one record, one sugar episode was crossed out, possibly as an attempt by the parent to portray that they had adhered to the recommended number of sugar intakes per day as directed by the dentist during their first visit (see Case 1, observation 1 extract below). This is an example of how multiple data sources collected in a sequence related to the use of a diet-diary helped to give us a deeper understanding of patients' experience and behavior.

\section{Clinicians priming the parents to think of the diet- diary as a "test"}

We found that dentists contributed to the diet-diary being seen as a test by parents, sometimes explicitly referring to the task of completing the diet-diary as a "test." In observations, clinicians were observed, perhaps unintentionally, priming the patients to provide the right answers by providing the dietary advice at the time of issuing the diet-diary. For example, in Case 1, the dentist provided comprehensive diet advice just before issuing the diet-diary. They emphasized the importance of having a maximum of four episodes of sugar consumption per day. This immediately preceded the issuing of the diet-diary.

Dentist: So, what we want to try and do is have no more than four sugar attacks a day. Okay. So, that's your breakfast, your lunch, your dinner, and one other time, and anything in between those four always try to be sugar free. So, the key thing is to try and cut out the juices, but if you can't, at least have it with your meal. Then anything in between the only things you can have really is water. It's not very nice; it's boring, isn't it? But between meals that's the idea. Is that alright with you?

Parent: That's fine.

Dentist: Another test? How many sugar attacks should you have a day?

Parent: Three.

Dentist: Well that would be perfect, but four is okay but three would be even better. Is that okay with you?

Parent: Yes.

Dentist: Are you sure?

Parent: Yes.

Dentist: Good. If you do the diet-diary for next time. Parent: Yes.

[Case 1, observation 1]

Observations showed that dentists tended to check patient's understanding of correct dietary behaviors by "marking" the diet-diary. The language used was paternalistic ("adult-child") rather than as two equal adults (dentistparent). With such a didactic approach, there was little opportunity for patients to participate on equal terms.

So, what have we got? Let's have a peek through these. So that first day there is only 4 sugar attacks which is kind of what we're aiming for. [Case 1, Dentist, observation 2] 
Now obviously, we want a nice balanced diet. We don't want you having bags and bags of unhealthy things. But at the same time, I am not saying cut it all out because that's not possible. Now I am going to be a bit mean now and go on about Ribena. Is that alright with you? [Case 1, dentist, observation 2]

\section{Theme 2: user's values, priorities, and circumstances}

Our study found that parents/carers were the usual keepers of diet-diaries, which meant that the way the diary was completed was inevitably influenced by parental values and views regarding oral health. Since keeping the diet record was onerous, competing other priorities contributed to the poor adherence observed, and in some cases parents then relied on their children to recall information. Consequently, the diary was far from a contemporaneous record. Sub-themes are described and evidenced below.

\section{Relative position of diet-diaries in the hierarchy of priorities}

Dentists attributed poor diet-diary adherence to a lack of motivation, reporting they felt parents of children with extensive tooth decay and poor oral hygiene were relatively unlikely to return a diet-diary.

I think people who have got wall to wall decayed teeth and they aren't maybe brushing their teeth properly may be less inclined to do it. If people aren't willing to go and brush their teeth and do that, then are they willing to fill in a diary? [Dentist interview, William]

Parents themselves reported struggling to fit the diet-diary into their everyday lives. Working parents, in particular, reported that they found it difficult to keep an eye on the child throughout the day and complete the diary task. This was especially complicated where the child was of schoolage and both parents worked.

Just life and being busy I suppose. Well, just being really honest, we both work full-time. She has after school activities every day so it's kind of like a full day anyway. Then it's just finding time for other things. [Case 3, parent, debrief interview]

I forgot the food diary, but I haven't got the time to do them ... the thing is ... just with me being at work and everything. She has got to go back to school and I have got to go back to work, I just don't have the time to do the thing. [Case 5, parent, observation 2]
In an effort to comply within the constraints of busy lives, some parents reported completing the diary retrospectively.

I was going to work on Friday afternoon and I realized "Oh the diary is here next to me on my seat," so we took it in and tried to fill it retrospectively. [Case 2, parent, follow-up interview]

Some parents reported relying on their children to keep the diary or to memorize their dietary intakes. This introduced a further possible bias in the account, where the child was reported as reluctant to fully disclose everything to their parents, for fear of reprimand and sanction. Thus, the validity of the account was influenced by the relationship between parents and the child

She (the child) kept the diary and we just sit with her at the end of the day to check that she did not forget things.

[Case 3, parent, follow-up interview]

I think the reason he would not maintain a food diary is probably because he doesn't want us to know how much sweets he has had. [Case 2, parent, follow-up interview]

\section{The parent-child relationship}

The child's co-operation was an important contribution in achieving a valid dietary record. Our data showed that parents only had partial control over/knowledge concerning the dietary behavior of their child, and that children exerted some influence on the extent of adherence in the diet-diary task.

So, what happens with him and his friends is they save up all the money for the, for the few days and then go buy sweets in the shop when they are walking home and in the past he'd never tell us about it but I have noticed that he has got wrappers in his pockets. [Case 2, parent, debrief interview]

Our findings concur with several other studies, that show children and parents actively negotiate rules around food and eating, even with very young children. ${ }^{23}$ The involvement of a dentist or dental team member in a dietary discussion was sometimes welcomed by parents as a means to strengthen their negotiations with their child. When observing the giving of dietary advice in the dental team, parents were often noted as asking the child to focus or to listen carefully when advice was given: and this was substantiated with interview data:

I think it will help me or help [child] more because he needs to know how much sugar is affecting his teeth and I think that is ... it's the ... I feel it's the drinks that are causing the decay but as much as I tell him he doesn't listen. But he 
seems to take on advice of other people, like dentists, doctors, he probably listens to them more. [Case 1, parent, debrief interview]

\section{A paper diet-diary format is outmoded and onerous} Parents reported that they found the paper diet-diary given difficult, labor intensive, and sometimes inaccessible, and this contributed to their response to using them properly.

Not having access to the diary is one. Of course, if you keep it somewhere else and you don't have it then you have to fill it in retrospectively. Also, if it's for a few days it's easy I will be very honest, and if it's for a longer duration than 3 or 4 days, then I think we tend to forget, don't we so? [Case 2, parent, follow-up interview]

The paper-based diaries were labeled as "old-fashioned." Mobile apps were suggested as a practical alternative, and more in keeping with the everyday lives of families involved.

I think what we thought when we discussed is nowadays everybody has phones and everybody has Smartphones. Apps are better I think. Having an app on the phone because people are always on their phone, even when they are talking to people on the phone. [Case 2, parent, debrief interview]

We were out on the Sunday; we did have an ice cream. So, I just kept a note on my phone if he had anything whilst we were out. [Case 5, parent, follow-up interview]

\section{Discussion}

Given that giving oral health education advice is a central activity in preventive dentistry, it is surprising that so few qualitative studies have been undertaken in this area, exploring how dietary advice is given and how it is received. ${ }^{9}$ This study shows that adherence to diet-diaries is a multicontextual phenomenon associated with an interaction of factors associated with the patient (parent/child), the dentist/ dental team, and the diet-diary itself. These factors are in essence similar to those recognized in the wider medical literature which influence the adherence to professional recommendations or medications, ${ }^{24-26}$ and previous literature on adherence to diet-diaries in nutritional research and dietary monitoring. ${ }^{11}$

A key finding in this study was that patients' perception, attitude, and motivation towards diet-diaries influenced their adherence to the diet-diary task. A major issue is that diet-diaries were perceived by parents as a "test," which is not helped by dentists, perhaps unwittingly, also presenting and framing it as such. "Hiding maneuvers"21 are perhaps then inevitable, since a previous qualitative study exploring the experiences of diet-diaries users in nutritional research reported a similar tendency to avoid negative feedback by modifying the dietary intakes or altering the record itself. ${ }^{27}$

The data suggests that dentists themselves contribute to this perception by adopting a paternalistic and controlling communication style when approaching the giving of advice. This appears to put patients at unease and drive them to see the diet-diary as a source of discomfort rather than a tool of support. Controlling and dominant behavior on the part of clinicians has been found to lower satisfaction in wider health care studies and, hence, lower adherence to their recommendations. ${ }^{28}$

Our study shows that diet-diaries compete with other duties within the busy lifestyle of the families involved. It has been suggested that the patients weigh up the costs and benefits of recommended courses of action within the circumstances and constraints of their everyday lives and needs. ${ }^{25}$ Therefore, adherence to diet-diaries can be contingent upon how highly the patient rates the diet-diary among other competing priorities of everyday life. In other words, an individual may not complete a trivial task such as the diet-diary, even if it is considered useful, at the expense of more essential duties and responsibilities, depending on their circumstances. Alternately, the patients may choose to keep the diary to the extent that fits their priorities and does not affect their daily routines. This study shows that busy parents may compromise and fill in the diary retrospectively or rely on the child to keep the diary. However, this undermines the quality of collected data by recall bias or child's incapability to provide an accurate record. ${ }^{29}$

The effect of the diet-diary form and nature of use is another issue affecting the adherence to its protocol. This study's findings are consistent with that of other studies in the field of dietary assessment and self-monitoring research, which suggested that the use of paper diaries for several consecutive days is an exhaustive and burdensome activity for many patients, and may result in under-reporting, altering the record and retrospective completion. ${ }^{11,30,31}$ What is more, using a paper format was found to be viewed as an impractical and outmoded vehicle in an era where digital options are available. Smart phones which are widely available and accessible, regardless of the time and the place, and easy to handle, ${ }^{32}$ may represent an effective alternative. Technology such as smart phones with camera capability have the capacity for easier and more timely recording techniques, 
such as taking and storing pictures of foods before and/or after eating, which could also reduce self-report error. ${ }^{33}$ Therefore, it could conceivably be hypothesized that using electronic rather than paper diaries would improve the use of diet-diaries as a tool of dietary assessment and self-monitoring.

The reliance on electronic diaries for dietary assessment and monitoring in health care generally is now preferable over paper diaries, which are currently being replaced. ${ }^{11,30}$ The use of mobile devices for dietary assessment and monitoring has shown superior acceptability, user satisfaction, and adherence to dietary self-monitoring when compared to paper-based diaries. ${ }^{30,34,35}$ However, while such advancements in technology are still subject to self-report bias and technical problems such as data transfer, storage and battery life, ${ }^{36}$ they have the potential to provide high quality and real-time dietary information. ${ }^{37}$ There is evidence that incorporating self-monitoring into dietary behavior interventions significantly increases effectiveness more than interventions that do not. ${ }^{38}$ It can, thus, be suggested that encouraging parents to use diet-diaries as a self-monitoring tool may increase their efficiency in supporting health dietary behaviors. There has yet to be any studies of this type in dentistry. Our study indicates that, when introducing this approach, the intervention approach will need to address dentists' attitudes and behavior concerning dietary assessments (so that they no longer introduce the activity as some sort of test to be passed), as well as parents' fear of being judged for permitting behavior that might cast them in a poor light as parents.

This study has some strengths, limitations, and methodological choices that are worth discussing. The use of a case study design has enabled the collection of data from multiple sources and the use of different collection strategies. Central to this is the use of observation, which allowed for studying the phenomenon in its natural setting. ${ }^{39}$ This was further informed by interviews and documentary analysis. Observations carry an inherent risk of observer effect bias, which is also called the "Hawthorne effect," and this means the participant might change their response because of their awareness of being observed. ${ }^{40}$ To minimize the observer effect, the researcher spent some time in the study setting before commencing data collection, so that the dentists become desensitized to the presence of other individuals. Similarly, the researcher was introduced early to parents and children in their first visit before carrying out the observation. ${ }^{41}$ In addition, the participants were assured about their confidentiality, and the aim of the study was explained to them.

Another possible weakness is the relatively small number of cases on which the study is based. While this may limit study generalizability to the general population, studies of this size are not unusual, since the primary focus of the investigation is the generation of hypotheses and insight so that these can be tested in a later phase with a wider number of participants.

\section{Conclusion}

In conclusion, while small scale and exploratory in nature, the study sheds light on several key factors associated with adherence with diet-diaries issued in a dental hospital setting. The findings of this study highlight the fact that patient's adherence to diet-diaries is influenced by a complex range of factors related to the diet-diary, the child, the parent, the dentist/dental team, and the interactions between them within the clinical environment.

\section{Acknowledgments}

The authors wish to thank all study participants.

\section{Author contributions}

All authors contributed toward data analysis, drafting and revising the paper and agree to be accountable for all aspects of the work.

\section{Disclosure}

The authors report no conflicts of interest in this work.

\section{References}

1. World Health Organisation WHO. Sugars intake for adults and children. Geneva, Switzerland: WHO; 2015.

2. Public Health of England. Delivering better oral health: an evidencebased toolkit for prevention. 3rd ed. London: PHE; 2014

3. Noar SM, Benac CN, Harris MS. Does tailoring matter? Meta-analytic review of tailored print health behavior change interventions. Psychol Bull. 2007;133(4):673-693.

4. Rugg-Gunn AJ, Nunn JH. Nutrition, diet and oral health. Oxford, UK: Oxford University Press; 1999.

5. Watt RG, McGlone P, Kay EJ. Prevention. Part 2: Dietary advice in the dental surgery. Br Dent J. 2003;195(1):27-31.

6. Wilkins EM, Wyche CJ. Clinical practice of the dental hygienist. $11^{\text {th }} \mathrm{ed}$. Philadelphia, PA: Lippincott Williams \& Wilkins; 2013.

7. Kidd E. Essentials of dental caries: the disease and its management. Oxford, UK: Oxford University Press; 2005.

8. Arheiam A, Brown S, Burnside G, Higham SM, Albadri S, Harris RV. The use of diet diaries in general dental practice in England. Community Dent Health. 2016;33:267-273.

9. Arheiam A, Albadri S, Brown S, Burnside G, Higham S, Harris R. Are diet diaries of value in recording dietary intake of sugars? A retrospective analysis of completion rates and information quality. Br Dent J. 2016; 221(9):571-576.

10. Glanz K, Murphy S, Moylan J, Evensen D, Curb JD. Improving dietary self-monitoring and adherence with hand-held computers: a pilot study. Am J Health Promot. 2006;20(3):165-170.

11. Thompson FE, Subar AF. Chapter 1 - Dietary assessment methodology. In: Coulston AM, Boushey CJ, Ferruzzi MG, eds. Nutrition in the prevention and treatment of disease. 3rd ed. Cambridge, MA: Academic Press; 2013: $5-46$. 
12. Gondolf UH, Tetens I, Hills AP, Michaelsen KF, Trolle E. Validation of a pre-coded food record for infants and young children. Eur J Clin Nutr. 2012;66(1):91-96.

13. Knudsen VK, Gille MB, Nielsen TH, Christensen T, Fagt S, BiltoftJensen A. Relative validity of the pre-coded food diary used in the Danish National Survey of Diet and Physical Activity. Public Health Nutr. 2011;14(12):2110-2116.

14. Yin RK. Case study research: design and methods. 5th ed. Thousand Oaks, CA: SAGE Publictions; 2014.

15. Merriam SB, Tisdell EJ. Qualitative research: A guide to design and implementation. San Francisco: John Wiley \& Sons; 2015.

16. Stake RE. Case studies. In: Denzin NK, Lincoln YS, eds. The Sage handbook of qualitative research. Thousand Oaks, CA: Sage; 2000.

17. Bowen GA. Naturalistic inquiry and the saturation concept: a research note. Qual Res. 2008;8(1):137-152.

18. Braun V, Clarke V. Using thematic analysis in psychology. Qual Res Psychol. 2006;3(2):77-101.

19. Bowen GA. Document analysis as a qualitative research method. Qual Res J. 2009;9:27-40.

20. Sbaraini A, Carter SM, Evans RW, Blinkhorn A. How to do a grounded theory study: a worked example of a study of dental practices. BMC Med Res Methodol. 2011;11:128.

21. Lazare A. Shame and humiliation in the medical encounter. Arch Intern Med. 1987;147(9):1653-1658.

22. Myers G. Risk and face: A review of the six studies. Health Risk Society. 2003;5(2):215-220.

23. Curtis P, James A, Ellis K. Children's snacking, children's food: food moralities and family life. Child Geog. 2010;8(3):291-302.

24. Garrity TF. Medical compliance and the clinician-patient relationship: a review. Soc Sci Med E. 1981;15(3):215-222.

25. Donovan JL, Blake DR. Patient non-compliance: deviance or reasoned decision-making? Soc Sci Med. 1992;34(5):507-513.

26. Kardas P, Lewek P, Matyjaszczyk M. Determinants of patient adherence: a review of systematic reviews. Front Pharmacol. 2013;4:91.

27. Vuckovic N, Ritenbaugh C, Taren DL, Tobar M. A qualitative study of participants' experiences with dietary assessment. J Am Diet Assoc. 2000;100(9):1023-1028.

28. Street RL Jr, Gordon H, Haidet P. Physicians' communication and perceptions of patients: is it how they look, how they talk, or is it just the doctor? Soc Sci Med. 2007;65(3):586-598.
29. Livingstone MB, Robson PJ, Wallace JM. Issues in dietary intake assessment of children and adolescents. Br J Nutr. 2004;92(Suppl 2): S213-S222.

30. Burke LE, Warziski M, Starrett T, et al. Self-monitoring dietary intake: current and future practices. J Ren Nutr. 2005;15(3):281-290.

31. Burke LE, Swigart V, Warziski Turk M, Derro N, Ewing LJ. Experiences of self-monitoring: successes and struggles during treatment for weight loss. Qual Health Res. 2009;19(6):815-828.

32. Lacson R, Long W. Natural language processing of spoken diet records (SDRs). AMIA Annu Symp Proc. 2006:454-458.

33. Thompson FE, Subar AF, Loria CM, Reedy JL, Baranowski T. Need for technological innovation in dietary assessment. J Am Diet Assoc. 2010;110(1):48-51.

34. Carter MC, Burley VJ, Nykjaer C, Cade JE. Adherence to a smartphone application for weight loss compared to website and paper diary: pilot randomized controlled trial. J Med Internet Res. 2013;15(4):e32.

35. Yon BA, Johnson RK, Harvey-Berino J, Gold BC, Howard AB. Personal digital assistants are comparable to traditional diaries for dietary self-monitoring during a weight loss program. J Behav Med. 2007;30(2):165-175.

36. Sun M, Fernstrom JD, Jia W, et al. A wearable electronic system for objective dietary assessment. J Am Diet Assoc. 2010;110(1):45-47.

37. Lieffers JR, Hanning RM. Dietary assessment and self-monitoring with nutrition applications for mobile devices. Can J Diet Pract Res. 2012;73(3):e253-e260.

38. Prestwich A, Kellar I, Parker R, et al. How can self-efficacy be increased? Meta-analysis of dietary interventions. Health Psychol Rev. 2014; $8(3): 270-285$.

39. Mills AJ, Eurepos G, Wiebe E. Encyclopedia of case study research. Thousand Oaks, CA: Sage Publications; 2009.

40. Caldwell K, Atwal A. Non-participant observation: using video tapes to collect data in nursing research. Nurse Res. 2005;13(2):42-54.

41. Polit-O'Hara D, Beck CT. Essentials of nursing research: Methods, appraisal, and utilization. Vol 1. Philadelphia: Lippincott Williams \& Wilkins; 2006. 


\section{Supplementary materials}

Parent/child interview topic guide
First Interview
Preamble
- Introduction of interviewer and explanation of research purpose
- Confirmation of interview confidentiality, anonymity in reporting the data, and the interview length
- Confirmation of interviewee's name and that he is happy for interview to be taped

Questions

- Can you tell me about yourself (your family, who you live with, what you do)?

- Can you tell me about the appointment today and what brought you here (have you been here before, has your child been here before, reason for referral)?

- Did you find the appointment useful (did they tell you things you didn't know before, was there anything new)?

- The dentist asked you to fill in a food diary - what do you think about that?

- Have you ever filled in a food diary? When, why, who asked you to fill it in?

- Do you think a food diary is relevant to you? Who do you think it is relevant for?

- Whose job will it be to complete the diet-diary? Who in your family do you think might complete it?

- Do you think it would be helpful for you to complete this? Who might it be helpful for? What do you expect to learn by completing the diary?

- Do you think it is important for you to complete this? Is it important for some people?

- Are there any reasons you might not be able to complete this?

Concluding comments

- Would it be useful for you to have a copy of the report and recommendations from this study?

- Thank you for your time. If I find that I need further clarification on any of the issues that we have talked about today, would it be OK to contact you again?

Follow-up interview

- Please tell me about your experience of using the food diary?

- Can you describe how you filled in the food diary? Where and when did you fill it in? Was it immediately after each meal or intake?

- Tell me what were the difficult and easy parts of completing it?

- Was anybody else involved in completing it? Who and why?

- What prevents you from completing the food diary?

- Do you notice any differences in your eating behavior?

- Do you think your behavior is changed from doing this?

- Do you think you will change your behaviors after doing it?

- Can you think of an easier way to do this?

Dentists' interview topic guide

Preamble

- Introduction of interviewer and explanation of research purpose

- Confirmation of interview confidentiality, anonymity in reporting the data, and the interview length

- Confirmation of interviewee's name and that he is happy for interview to be taped

Questions

- Please tell me about yourself (education, work experience, etc)

- Please tell me about your experience of using food diary

- What are you aiming for by using diet-diaries?

- In your opinion, what are the weaknesses and strengths of using diet-diaries?

- Which kind of patients do you think diet-diaries should be used for?

- Do patients usually return diet-diaries? If not, why? What are the common excuses given by patients who do not return the diaries?

- What kind of information do patients usually forget to record?

- What do you usually do when the patients do not bring back the diet-diary or bring incomplete ones?

Concluding comments

- Would it be useful for you to have a copy of the report and recommendations from this study?

- Thank you for your time. If I find that I need further clarification on any of the issues that we have talked about today, would it be OK to contact you again?

Figure SI (Continued) 


\begin{tabular}{|l|}
\hline Location \\
Dental \\
Hospital \\
Actors Dentist: Parent: Child: \\
Observation performa \\
Sequencing of events \\
- Who come in? \\
- Who comes first? \\
- Do they shake hands? \\
- Who starts the conversation? \\
- Where does the mother sit? \\
- What is the child doing? \\
- Who is it addressed to? \\
- Where is the eye contact? \\
- What is happening at the time of giving instruction? (passive vs active involvement) \\
- What is body language that makes you think that? \\
- Was the child interested? \\
- $\quad$ Parent and child interactions: \\
- $\quad$ Other notes:
\end{tabular}

Figure SI Topic guide for interviews and observation performa.

\section{Publish your work in this journal}

Patient Preference and Adherence is an international, peer-reviewed, open access journal that focuses on the growing importance of patient preference and adherence throughout the therapeutic continuum. Patient satisfaction, acceptability, quality of life, compliance, persistence and their role in developing new therapeutic modalities and compounds to optimize clinical outcomes for existing disease states are major areas of interest for the journal. This journal has been accepted for indexing on PubMed Central The manuscript management system is completely online and includes a very quick and fair peer-review system, which is all easy to use. Visit http://www. dovepress.com/testimonials.php to read real quotes from published authors.

\footnotetext{
Submit your manuscript here: http://www.dovepress.com/patient-preference-and-adherence-journal
} 